\title{
Increased mucosal tumour necrosis factor $\alpha$ production in Crohn's disease can be downregulated ex vivo by probiotic bacteria
}

\author{
N Borruel, M Carol, F Casellas, M Antolín, F de Lara, E Espín, J Naval, F Guarner, \\ J R Malagelada
}

See end of article for authors' affiliations

Correspondence to: Dr F Guarner, Digestive System Research Unit, Hospital General Vall d'Hebron, Barcelona 08035, Spain;

fguarnera@medynet.com

Accepted for publication 18 March 2002

\begin{abstract}
Background and aims: Tumour necrosis factor $\alpha$ (TNF- $\alpha$ ) plays a key role in the pathogenesis of intestinal inflammation in Crohn's disease. The effect of bacteria on TNF- $\alpha$ release by intestinal mucosa was investigated.

Methods: Ileal specimens were obtained at surgery from 10 patients with Crohn's disease (ileal stricture) and five disease controls undergoing right hemicolectomy (caecal cancer). Mucosal explants from each specimen were cultured for 24 hours with either non-pathogenic Escherichia coli, Lactobacillus casei DN-1 14001, L bulgaricus LB10, or L crispatus (each study contained blank wells with no bacteria). Tissue and bacterial viability was confirmed by lactate dehydrogenase (LDH) release and culture. Concentrations of TNF- $\alpha$ were measured in supernatants and the phenotype of the intestinal lymphocytes was analysed by flow cytometry.

Results: Coculture of mucosa with bacteria did not modify LDH release. Release of TNF- $\alpha$ by inflamed Crohn's disease mucosa was significantly reduced by coculture with $L$ casei or L bulgaricus; changes induced by $L$ crispatus or $E$ coli were not significant. The effect of $L$ casei and $L$ bulgaricus was not prevented by protease inhibitors. Coculture with $L$ casei and $L$ bulgaricus reduced the number of CD4 cells as well as TNF- $\alpha$ expression among intraepithelial lymphocytes from Crohn's disease mucosa. None of the bacteria induced changes in non-inflamed mucosa.

Conclusions: Probiotics interact with immunocompetent cells using the mucosal interface and modulate locally the production of proinflammatory cytokines.
\end{abstract}

U nrestrained activation of the intestinal immune system appears to be responsible for the characteristic relapsing course of inflammatory bowel disease. ${ }^{1}$ The recurrent disease process may be mediated by an abnormal pattern of cytokine release. In Crohn's disease, the potent proinflammatory cytokine tumour necrosis factor $\alpha(\mathrm{TNF}-\alpha)$ seems to play a pivotal role in the pathogenesis of altered mucosal immune function. ${ }^{23}$ Several lines of evidence support this concept. Firstly, expression of TNF- $\alpha$ in the intestinal mucosa is increased in patients with Crohn's disease. ${ }^{4-8}$ Secondly, a number of clinical studies using anti-TNF- $\alpha$ monoclonal antibody therapy have clearly shown a beneficial response associated with clinical, endoscopic, and histological remission. ${ }^{-14}$ Furthermore, failure of anti-TNF- $\alpha$ therapy has been related to early reactivation of TNF- $\alpha$ secretory capacity by immunocompetent cells. ${ }^{15}$ These observations together with evidence obtained from in vitro studies ${ }^{16}{ }^{17}$ led to the notion that enhanced function of $\mathrm{T}$ helper 1 lymphocytes that secrete TNF- $\alpha$ is a key factor in the pathogenesis of Crohn's disease. ${ }^{318}$

The resident flora represent a major challenge to the intestinal immune system and an abnormal immunological reactivity to normal flora has been clearly documented in patients with Crohn's disease. ${ }^{19}{ }^{20}$ Unrestrained activation of the intestinal immune system in Crohn's disease patients may result from lack of tolerance to the resident flora. In experimental studies, non-pathogenic bacteria of the enteric flora have been shown to induce inflammatory responses and mucosal injury. ${ }^{21-24}$ Certain genera such as Bacteroides and Clostridium may be detrimental when dysfunction of the colonic mucosal barrier is present, ${ }^{22}{ }^{23}$ whereas Bifidobacterium and Lactobacillus are considered beneficial. Injection of lactobacilli into the rat intestinal wall does not induce an inflammatory reaction, as opposed to injection of Bacteroides and Clostridium species. ${ }^{23}$ Moreover, Lactobacillus reuteri can prevent intestinal inflammation in interleukin 10 (IL-10) deficient mice. ${ }^{25}$ Several studies suggest that colonising bacteria play a major role in the growth and differentiation of gut associated lymphoid tissue, and different bacteria may elicit different responses. ${ }^{26}{ }^{27}$ Non-pathogenic bacteria may modify immune responses of the intestinal mucosa by interaction and signalling at mucosal surfaces. ${ }^{28}$

The aim of the current study was to investigate whether bacteria modulate cytokine responses in Crohn's disease. To this end, we incubated mucosal explants from Crohn's disease patients and controls in the presence of different bacteria, including two strains with known probiotic properties.

\section{METHODS \\ Patients}

Samples of intestinal mucosa were obtained at surgery from 10 patients with Crohn's disease (six men and four women; median age 32 years (range 20-67)) undergoing ileal resection for ileal stricture unresponsive to conventional medical treatment. All patients had been treated with oral corticosteroids (prednisolone $0.5-1.0 \mathrm{mg} / \mathrm{kg} /$ day) and azathioprine (2-2.5 $\mathrm{mg} / \mathrm{kg} /$ day) up to the time of surgery and tissue sampling. The diagnosis of Crohn's disease was established by routine clinical, radiological, and endoscopic criteria and confirmed by

Abbreviations: CFU, colony forming units; IEL, intraepithelial lymphocytes; IL, interleukin; LDH, lactate dehydrogenase; LPL, lamina propria lymphocytes; LB broth, Luria Bertani broth; MRS broth, Man-Rogosa-Sharpe broth; TNF- $\alpha$, tumour necrosis factor $\alpha$. 
histological examination. Ileal stricture was diagnosed on the basis of clinical symptoms and imaging studies (small bowel barium studies and computed tomography scan). Macroscopic examination of the surgical specimen confirmed ileal stricture in all patients, and histological examination demonstrated transmural inflammation, intense fibrosis, lymphoid aggregates in the submucosa, and granulomas. Control ileal specimens were obtained from five patients undergoing right hemicolectomy for colonic cancer located at the caecum (three men and two women; median age 67 years (range 45-78)). Preparation for surgery was similar for patients and controls, and included gut lavage with electrolyte-polyethylene glycol solution and broad spectrum antibiotic therapy. The project was approved by the local ethics committee (CEIC, Hospitals Vall d'Hebron).

\section{Organ culture}

Full thickness ileal wall specimens, including areas with and without macroscopic lesions, were collected at surgery. After resection specimens were rinsed under a jet of saline and gently washed twice in sterile saline. They were immediately transferred to our laboratory in sterile saline at $4^{\circ} \mathrm{C}$. Multiple mucosal samples weighing 20-30 mg each were separated from underlying tissue and placed on culture filter plates (15 mm diameter wells with $500 \mu \mathrm{m}$ bottom-mesh; Netwell Culture Systems, Costar, Cambridge, Massachusetts, USA). The epithelial surface was uppermost. Filters were suspended over wells containing $1500 \mu \mathrm{l}$ medium, consisting of RPMI 1640 (CanSera, Rexdale, Ontario, Canada) supplemented with $10 \%$ fetal calf serum (Gibco BRL, Eggenstein, Germany), 100 $\mathrm{U} / \mathrm{ml}$ penicillin (Normon, Madrid, Spain), $100 \mu \mathrm{g} / \mathrm{ml}$ streptomycin (Normon), and $50 \mu \mathrm{g} / \mathrm{ml}$ gentamycin (Normon). Samples were preincubated with antibiotics for one hour at $37^{\circ} \mathrm{C}$ in a humidified $5 \% \mathrm{CO}_{2}$ atmosphere to eradicate indigenous flora and equilibrate the tissue to the culture conditions. Thereafter, medium was replaced by fresh RPMI 1640 supplemented with $10 \%$ fetal calf serum, sodium bicarbonate $24 \mathrm{mmol} / \mathrm{l}$, and 100 $\mathrm{U} / \mathrm{ml}$ penicillin. Sodium bicarbonate was added to prevent acidification of the medium by bacterial metabolism and penicillin to prevent bacterial overgrowth. Selected bacteria strains were added to the incubation at appropriate concentrations, as described below. Each study run included blank wells with no bacteria in the organ culture. After 24 hours at $37^{\circ} \mathrm{C}$ in a $5 \% \mathrm{CO}_{2}$ chamber, supernatants and tissues were collected and stored at $-80^{\circ} \mathrm{C}$ until analysis. In ancillary experiments, a mix of protease inhibitors including protease inhibitor cocktail for mammalian cells $(0.6 \mu \mathrm{l} / \mathrm{ml}$; P-8340, SigmaAldrich, Madrid, Spain) and protease inhibitor cocktail for bacteria extracts ( $1.3 \mu \mathrm{l} / \mathrm{ml}$; P8465, Sigma-Aldrich) was added to the incubation medium.

\section{Bacterial strains}

Lactobacillus casei DN-114001 and Lactobacillus bulgaricus LB10 were provided by Danone Vitapole (Paris, France). Consumption of $L$ casei DN-114001 was shown to increase the percentage of children with high counts of lactobacilli in faeces, ${ }^{29}$ and to reduce the severity of incident episodes of acute diarrhoea during a six month controlled trial among infants attending day care centres. ${ }^{30} \mathrm{~L}$ crispatus was provided by Dr Antonia Andreu (Microbiology Department, Hospital Vall d'Hebron). This strain had been isolated from the human vaginal flora and selected because of its capacity to inhibit the growth of uropathogens. ${ }^{31}$ A non-pathogenic Escherichia coli strain (ECOR-26) from the Ochman-Selander collection of standard reference strains of $E$ coli isolated from natural populations ${ }^{32}$ was provided by Professor Juan Aguilar (Biochemistry, Faculty of Pharmacy, University of Barcelona, Spain). Lactobacilli were grown in Man-Rogosa-Sharpe liquid medium (MRS broth; Difco, Detroit, Michigan, USA) and the $E$ coli strain in Luria Bertani broth (LB, Pharmacy, Hospital Vall d'Hebron) at $37^{\circ} \mathrm{C}$ under aerobic conditions for 24 hours. Bacteria were harvested in the stationary phase, cell counts in the bacterial suspension were estimated by optical density at $600 \mathrm{~nm}$ absorbance (UV1601, Shimadzu, Kyoto, Japan), and bacteria were added to the tissue culture wells at the appropriate dilution to reach a final concentration of $10^{6}$ colony forming units $/ \mathrm{ml}$ of incubation medium. Aliquots of the suspensions were incubated in MRS or blood-agar plates to confirm bacterial growth and exclude the presence of contaminant bacteria.

In ancillary experiments, bacterial concentration in the supernatants of the organ culture was estimated by optical density readings after four and 24 hours of incubation $(n=5$ per bacteria and per time point). Optical density readings were transformed to bacteria counts by means of a specific conversion factor previously estimated for each strain, and data expressed as per cent of the counts at time 0. Other experiments ( $\mathrm{n}=5$ per bacteria and five blanks) assessed bacterial viability at the end of the incubation period by quantitative culture of the supernatant. After 24 hours of incubation, supernatants were spun at $9000 \mathrm{~g}$ for one minute using a benchtop Eppendorf centrifuge (Cologne, Germany), and the pellets washed twice in fresh liquid growth medium (MRS or LB). The resuspended pellets were plated on MRS or blood-agar at serial dilutions. Plates were incubated at $37^{\circ} \mathrm{C}$ for up to four days and colonies counted.

Other organ culture experiments investigated the effect of heat killed bacteria on TNF- $\alpha$ release compared with viable bacteria. For this purpose, aliquots of the bacterial suspensions were incubated for 10 minutes in a bath at $75^{\circ} \mathrm{C}$ whereas matched aliquots were kept at room temperature. Thereafter, tissue culture wells were inoculated with the suspensions at the appropriate dilution for the organ culture experiments. Aliquots of both suspensions were plated on MRS or blood-agar. No bacterial growth was observed in aliquots subjected to heat treatment whereas the matched aliquots showed growth of the corresponding bacterial strain only.

\section{Isolation of intestinal lymphocytes}

Cell populations were isolated after culture of ileal mucosa for 24 hours at $37^{\circ} \mathrm{C}$ with $5 \% \quad \mathrm{CO}_{2}$, as described above. Macroscopically inflamed samples from eight patients with Crohn's disease and normal appearing samples from four controls were included in the study. Intraepithelial lymphocytes (IEL) and lamina propria lymphocytes (LPL) were isolated as previously described. ${ }^{33}$ Briefly, mucosal samples were incubated in Iscove medium (Gibco) supplemented with $40 \mathrm{mg} / \mathrm{ml}$ gentamycin, $10 \%$ fetal calf serum, and 1 mM EDTA (Sigma-Aldrich) for one hour at $37^{\circ} \mathrm{C}$ under continuous stirring. Thereafter, IEL and epithelial cells were collected in the supernatant. Histological examination of the remaining fragment revealed that the villous and lamina propria structures were still preserved whereas all of the cells within the epithelium had disappeared during the procedure. The remaining fragments were then cut into small pieces and incubated under stirring for one hour at $37^{\circ} \mathrm{C}$ in Iscove medium containing $1 \mathrm{mg} / \mathrm{ml}$ collagenase-dispase (SigmaAldrich), and LPL were collected in the supernatant. The numbers of mononuclear cells were counted using a Bürker chamber, and the percentages of $\mathrm{CD} 3+$ lymphocytes were estimated by flow cytometry.

\section{Phenotypic analysis of intestinal T lymphocytes}

Phenotypic characterisation of the intestinal lymphocytes was performed by flow cytometry on isolated IEL and LPL. Cell suspensions were directly resuspended in complete Iscove medium at $1 \times 10^{6}$ cells $/ \mathrm{ml}$ and $100 \mu \mathrm{l}$ of the cell suspension was incubated with anti-CD3 FITC, anti-CD4 APC, anti-CD8 PerCPE, and anti-CD25 PE mAbs (Becton Dickinson, San Jose, California, USA) at $4^{\circ} \mathrm{C}$ for 30 minutes in the dark. After staining, cells were washed, and at least 5000 cells were analysed by flow cytometry (FACScan, Becton Dickinson). 
Table 1 Tissue viability after 24 hours of organ culture

\begin{tabular}{lccl}
\hline & Control & $\begin{array}{l}\text { Non-inflamed } \\
\text { Crohn's disease }\end{array}$ & $\begin{array}{l}\text { Inflamed } \\
\text { Crohn's disease }\end{array}$ \\
\hline Blank & $81(4.5)$ & $105(10.9)$ & $63(3.9)$ \\
L casei & $84(8.6)$ & $94(7.7)$ & $70(8.3)$ \\
L bulgaricus & $76(4.5)$ & $96(9.8)$ & $60(4.6)$ \\
L crispatus & $82(4.3)$ & $86(6.5)$ & $64(9.5)$ \\
E coli & $84(4.7)$ & $99(6.1)$ & $69(7.5)$ \\
\hline
\end{tabular}

Data are $\mathrm{mU}$ of lactate dehydrogenase/mg of tissue protein/hour, as measured in the supernatant after the 24 hour organ culture period (mean (SEM) of 10-14 organ culture experiments per point).

Lymphocytes were gated by forward-sideward scatter light and by gating for $\mathrm{CD} 3+$ cells.

The phenotype of TNF- $\alpha$-producing cells was analysed using flow cytometry by labelling both intracytoplasmic TNF- $\alpha$ and lymphocyte membrane markers. However, because this method lacks sensitivity, cells were first stimulated in vitro with phorbol-12-myristate-13-acetate and the calcium ionophore A23187 (10 $\mu \mathrm{g} / \mathrm{ml}$ and $100 \mu \mathrm{g} / \mathrm{ml}$; Sigma-Aldrich) in the presence of brefeldin A ( $10 \mu \mathrm{g} / \mathrm{ml}$; Sigma-Aldrich) for 16 hours at $37^{\circ} \mathrm{C}$ and $5 \% \mathrm{CO}_{2}$. Intestinal cytokine producing cells were analysed according to the instructions of the manufacturer of the Cytofix/Cytoperm product (Pharmingen, San Diego, California, USA) using monoclonals anti-CD3 FITC, anti-CD4 APC, anti-CD8 PerCP, and anti-TNF- $\alpha$ PE (Becton Dickinson). Results were expressed as percentage of positive cells per CD3 + cell. The cut off point at which a specific signal was considered positive was determined using cells stained with control antibodies of the same isotype.

\section{Analytical methods}

Concentrations of TNF- $\alpha$ in the supernatants were measured using a commercially available assay system for human TNF- $\alpha$ (DuoSet, R\&D Systems, Minneapolis, Minnesota, USA). All samples were analysed in duplicate. Results of cytokine concentrations are expressed as $\mathrm{pg} / \mathrm{ml}$ of culture medium.

Supernatants were analysed for lactate dehydrogenase $(\mathrm{LDH})$ using the spectrophotometric method of Krieg and colleagues. ${ }^{34}$ Tissue samples were homogenised in Tris/HCl (100 mmol/l, pH 7.4) and protein concentration was determined using the bicinchoninic acid reagent for protein assay (Pierce, Rockford, Illinois, USA). Tissue viability was assessed based on release of LDH/mg of tissue protein, according to Finnie and colleagues. ${ }^{35}$

\section{Statistical methods}

Results are expressed as mean (SEM) or median (range), as indicated. Statistical differences were determined using overall analysis of variance and the Student-Newman-Keuls method as post test for parametric variables, or the Kruskal-Wallis test and Dunn's post test for non-parametric variables (GraphPad Instat, San Diego, California, USA).

\section{RESULTS}

\section{Organ culture}

Table 1 shows mean $\mathrm{LDH}$ release, as measured at the end of the organ culture experiments. Interestingly, coculture of the tissue with any of the bacteria did not modify LDH release. Compared with total tissue LDH content, release of LDH into the medium during the 24 hour culture period was below 30\% in all experiments.

Concentrations of $L$ case $i$ in the organ culture supernatant, as assessed by optical density, decreased after four hours of incubation ( 75 (9)\% of baseline) but were relatively stable up to the end of the experiment (84 (7)\% at 24 hours). A similar

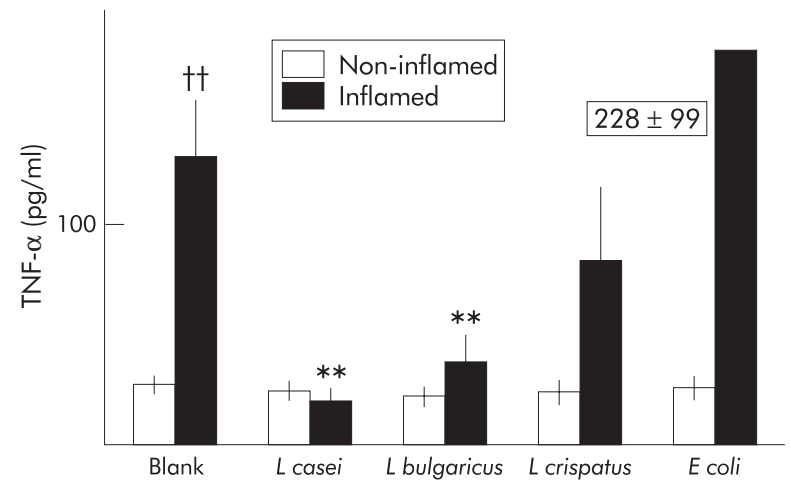

Figure 1 Levels of tumour necrosis factor $\alpha$ (TNF- $\alpha$ ) in the incubation medium after 24 hours of culture of intestinal mucosa from Crohn's disease patients in macroscopically non-inflamed mucosa or inflamed mucosa. No bacterium was added to blank cultures whereas Lactobacillus casei, L bulgaricus, L crispatus, or Escherichia coli were added at $10^{6}$ colony forming units $/ \mathrm{ml}$ in the corresponding culture wells. In blank cultures, levels of TNF- $\alpha$ were significantly higher in inflamed than in non-inflamed mucosa. Coculture of inflamed mucosa with $L$ casei or $L$ bulgaricus significantly reduced TNF- $\alpha$ levels. Data are mean (SEM): $\uparrow \uparrow p<0.01$ versus non-inflamed; ** $\mathrm{p}<0.01$ versus blank.

profile was observed for $L$ crispatus ( $80(9) \%$ at four hours and $73(8) \%$ at 24 hours). Concentrations of $L$ bulgaricus initially showed a marked drop (52 (8)\% at four hours) but remained stable (45 (7)\% at 24 hours), and $E$ coli concentrations increased over time (206 (84)\% at 24 hours). Microbiological culture of the supernatants after the 24 hour incubation period demonstrated growth of the same bacterial strain that had been inoculated previously, and no other bacterium was recovered. In blank incubations, no bacterial growth was found. Quantitative culture demonstrated concentrations of viable bacteria ranging from $9 \times 10^{4}$ to $5 \times 10^{5}$ colony forming units $/ \mathrm{ml}$ for $L$ casei, from $8 \times 10^{2}$ to $9 \times 10^{3}$ for $L$ bulgaricus, from $2 \times 10^{3}$ to $2 \times 10^{5}$ for $L$ crispatus, and above $1 \times 10^{6}$ for $E$ coli.

\section{Release of TNF- $\alpha$}

Concentrations of TNF- $\alpha$ in culture wells after 24 hours of incubation showed significant differences, as depicted in fig 1 . In blank organ cultures, release of TNF- $\alpha$ from inflamed tissue of Crohn's disease patients was significantly higher than release measured in non-inflamed tissue from the same patients $(p<0.01)$. Interestingly, coculture of inflamed tissue with the $L$ casei strain significantly reduced TNF- $\alpha$ release, and levels remained similar to those found in non-inflamed tissue. A similar effect was found in coculture experiments with $L$ bulgaricus. However, L crispatus and the non-pathogenic $E$ coli strain did not induce significant changes in TNF- $\alpha$ release by inflamed tissue compared with blank cultures. None of the bacterial strains tested induced changes in non-inflamed tissue from Crohn's disease patients. Likewise, release of TNF- $\alpha$ by ileal tissue from controls was similar in blanks ( 8 (2) $\mathrm{pg} / \mathrm{ml}), L$ casei ( $10(3)), L$ bulgaricus (6 (1.2)), L crispatus (6 (1)), and $E$ coli ( $10(3))$.

The effect of bacteria on TNF- $\alpha$ release by inflamed ileal tissue from Crohn's disease patients was tested in the presence of protease inhibitors added to the incubation medium. As shown in table $2, L$ casei and $L$ bulgaricus significantly reduced TNF- $\alpha$ levels in the presence of the protease inhibitor cocktail. These data suggest that the effect of the bacteria is not due to TNF- $\alpha$ degradation by bacterial proteases.

Table 3 shows release of TNF- $\alpha$ by inflamed ileal tissue from Crohn's disease patients in coculture experiments with either viable or dead bacteria. As previously observed, coculture of the tissue with both $L$ casei and $L$ bulgaricus significantly reduced release of TNF- $\alpha$. A statistically significant effect was only observed when viable bacteria were added to the organ culture. 
Table 2 Effect of bacteria on tumour necrosis factor $\alpha$ (TNF- $\alpha$ ) release by inflamed ileal tissue from Crohn's disease patients in the presence of protease inhibitors

\begin{tabular}{ll}
\hline & TNF- $\alpha(\mathrm{pg} / \mathrm{ml})$ \\
\hline Blank & $51(6.4)$ \\
L casei & $19(1.7)^{* *}$ \\
L bulgaricus & $26(4.4)^{* *}$ \\
\hline
\end{tabular}

** $p<0.01$ versus blank

Data are mean (SEM) of six organ culture experiments per point. A mix of protease inhibitors was added to the incubation medium of blanks and bacterial cocultures.

Table 3 Release of tumour necrosis factor $\alpha$ (TNF- $\alpha$ ) by inflamed ileal mucosa from Crohn's disease patients in coculture experiments with either viable or heat killed bacteria

\begin{tabular}{lc}
\hline & TNF- $\alpha(\mathrm{pg} / \mathrm{ml})$ \\
\hline Blank & $107(28.9)$ \\
L casei & \\
$\quad$ Viable & $8(3.6)^{*}$ \\
$\quad$ Heat killed & $60(9.6) \dagger$ \\
L bulgaricus & \\
$\quad$ Viable & $30(9.3)^{*}$ \\
$\quad$ Heat killed & $50(18.6)$ \\
\hline
\end{tabular}

${ }^{*} p<0.05$ versus blank; $\uparrow p<0.05$ versus viable bacteria.

Data are mean (SEM) of 4-6 organ culture experiments per point.

\section{Phenotypic analysis of intestinal T lymphocytes}

Table 4 shows cell counts in normal appearing mucosa from control individuals and in inflamed tissue from Crohn's disease patients after 24 hours of organ culture in the presence of bacteria. Incubation of inflamed tissue with $L$ casei significantly decreased the number of CD3+ cells in the epithelial compartment, and also the proportion of CD4+ cells and TNF- $\alpha$ expression among CD $3+$ cells. Relative changes induced by bacteria in the phenotype of IEL in inflamed tissue from Crohn's disease patients compared with blank incubations are shown in fig 2. Coculture of inflamed tissue with $L$ casei or L bulgaricus significantly reduced the rate of CD4+ cells. Moreover, TNF- $\alpha$ expression among CD3 + was significantly reduced in inflamed tissue incubated with $L$ casei or $L$ bulgaricus. Coculture of Crohn's disease tissue with $E$ coli had no significant effect. On the other hand, none of the bacteria induced any change in IEL phenotype in intestinal samples from control individuals (table 4).

Phenotypic changes were also observed in LPL from Crohn's disease inflamed tissue. After coculture with $L$ casei or $L$ bulgaricus, expression of $\mathrm{CD} 25$ in $\mathrm{CD} 3+$ cells was significantly reduced ( $L$ casei: median $64 \%$ of blank, range $49-86, \mathrm{p}<0.05 ; L$ bulgaricus: $77 \%, 39-98, \mathrm{p}<0.05)$. Expression of TNF- $\alpha$ in CD3+ cells was also below levels observed in parallel blank cultures in all but one of the patients studied ( $L$ casei: 77\%, 52-103; L bulgaricus: 96\%,94-106). No change was induced by coculture with $E$ coli. None of the bacteria induced any change in the phenotype of LPL in samples from controls.

\section{DISCUSSION}

Coculture of human ileal mucosa with bacteria resulted in adequate tissue viability, as shown by release of LDH from
Table 4 Phenotypic analysis of intestinal intraepithelial T lymphocytes (IEL) after coculture with bacteria

\begin{tabular}{lll}
\hline & Control mucosa & $\begin{array}{l}\text { Inflamed mucosa } \\
\text { Crohn's disease }\end{array}$ \\
\hline CD3 (\% of cells) & $15(3-17)$ & $6(2-13)$ \\
Blank & $17(2-21)$ & $4(1-7)^{*} \dagger$ \\
L casei & $13(3-17)$ & $4(1-10) \dagger$ \\
L bulgaricus & $16(5-19)$ & $6(1-14)$ \\
$E$ coli & & \\
CD4 $(\%$ of CD3) & $32(15-69)$ & $50(31-61)$ \\
Blank & $33(14-53)$ & $36(18-63)^{*}$ \\
L casei & $29(16-57)$ & $40(24-56)$ \\
L bulgaricus & $29(27-61)$ & $39(24-71)$ \\
$E$ coli & & \\
TNF- $\alpha \%$ of CD3) & $3(1-17)$ & $49(4-77)$ \\
Blank & $3(2-9)$ & $23(2-58)^{\star} \dagger$ \\
L casei & $3(1-8)$ & $35(3-75) \dagger$ \\
L bulgaricus & $5(3-18)$ & $53(3-73)$ \\
$E$ coli &
\end{tabular}

${ }^{*} \mathrm{p}<0.05$ versus blank; $\dagger \mathrm{p}<0.05$ versus $E$ coli.

Data are median (range) (four control individuals and eight Crohn's disease patients).

TNF- $\alpha$, tumour necrosis factor $\alpha$

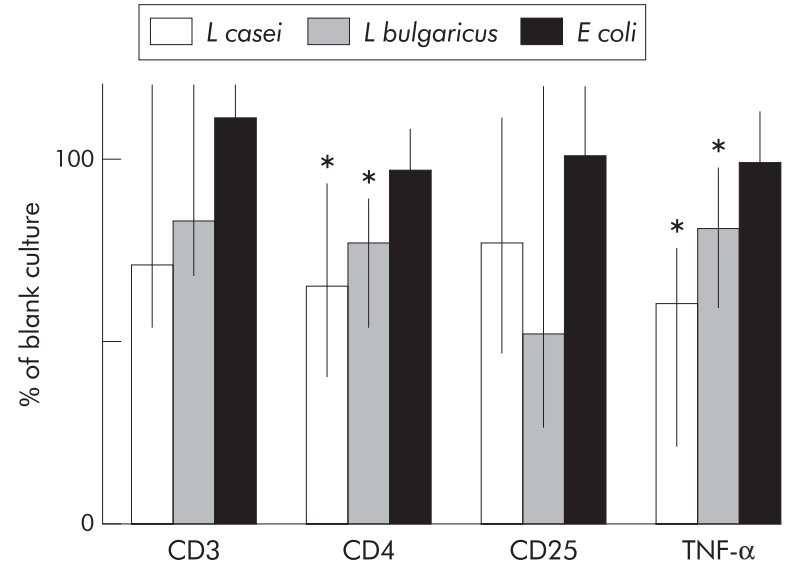

Figure 2 Phenotype of intraepithelial lymphocytes from inflamed mucosa of Crohn's disease patients normalised as a percentage of the data in blank cultures of mucosa from the same individual $(100 \%)$. Coculture with Lactobacillus casei or L bulgaricus reduced CD4+ cell numbers, as well as expression of tumour necrosis factor $\alpha(T N F-\alpha)$. Coculture with Escherichia coli had no effect on CD3, CD4, CD25, or TNF- $\alpha$. Data are median (range): ${ }^{*} p<0.05$ versus blank.

specimens in culture over the 24 hour period. Release rates were similar to those reported by Finnie and colleagues ${ }^{35}$ using mucosal explants from normal human colon. It must be emphasised that no change in LDH release was induced by the presence of bacteria in the incubation medium, as shown in cocultures with both inflamed and non-inflamed mucosa. In contrast, we observed that bacteria added to the organ culture remained at stable concentrations during the incubation period and viable at the end of the experiment, in agreement with a previous report by other investigators who employed lactic acid bacteria in coculture with human epithelial cell lines. ${ }^{36}$ Our estimates of bacterial concentration in the incubation medium by optical density were higher than recoveries of viable bacteria, as assessed by quantitative culture of the supernatants. The discrepancy may be due to either the presence of non-viable bacteria in the incubation medium or to impaired bacterial growth due to traces of penicillin in the samples plated for bacterial culture. Taken together, our data showed that both tissue and bacteria can be cultured together 
with adequate viability. Thus our model provides a validated approach for examining interactions between luminal bacteria and the host mucosa using the mucosal interface and the immunocompetent cells in their own natural disposition.

The principal objective of the study was to determine whether certain bacterial strains could modulate spontaneous production of TNF- $\alpha$ by intestinal mucosal specimens from patients with Crohn's disease. Indeed, our results showed that in patients with active Crohn's disease there is increased release of TNF- $\alpha$ by inflamed as compared with non-inflamed ileal mucosa. This finding is in agreement with previous evidence that intestinal production of TNF- $\alpha$ is increased in patients with Crohn's disease, using different methodological approaches, ${ }^{4-8}$ including organ culture of intestinal biopsy specimens. ${ }^{6}$ Remarkably however when inflamed mucosa was incubated in the presence of $L$ casei or $L$ bulgaricus there was an impressive reduction in the release of TNF- $\alpha$.

Our study is the first to report a modulating effect of bacteria on cytokine production by inflamed intestinal mucosa, a finding that we consider of great potential significance. $L$ case $i$ and $L$ bulgaricus markedly reduced production of TNF- $\alpha$ by inflamed mucosa whereas $L$ crispatus and $E$ coli had no significant effect. The non-pathogenic $E$ coli strain actually increased release of the cytokine in some patients, an observation consistent with the lack of tolerance towards common bacterial antigens that has been described in Crohn's disease ${ }^{19}{ }^{20}$ but the overall effect did not reach statistical significance. The effect of $L$ casei and $L$ bulgaricus was only observed in cocultures with inflamed mucosa as no change in TNF- $\alpha$ release was found in experiments with non-inflamed Crohn's disease and control mucosa. Interestingly, viable bacteria induced the full effect on TNF- $\alpha$ production whereas heat killed bacteria did not induce statistically significant changes. An effect due to bacteria cell fragments cannot be excluded but our current data suggest that products freshly derived from viable bacteria play a major role on modulation of TNF- $\alpha$ production by inflamed intestinal tissue. Previous in vitro studies with several Lactobacillus species including $L$ bulgaricus suggested that lactobacilli stimulate the release of TNF- $\alpha$ and IL- 6 by macrophages ${ }^{37}$ and activate nuclear factor $\kappa \beta$ in human leucocytes ${ }^{38}$ when bacteria are directly exposed to effector cells. However, oral administration of the strains did not induce changes in ex vivo TNF- $\alpha$ production by cultured leucocytes isolated from mice fed lactobacilli. ${ }^{39}$ Taken together, these observations suggest that responses of immunocompetent cells towards interacting bacteria may differ whether the interaction takes place at the mucosal surface or at a systemic level, but this concept has not been demonstrated.

The reduction in TNF- $\alpha$ levels in the incubation medium when inflamed mucosa was cultured with lactobacilli could not be explained by enhanced degradation of TNF- $\alpha$ due to proteases of bacterial origin as bacteria reduced TNF- $\alpha$ levels even in the presence of protease inhibitors. Thus ancillary experiments examined the effector immunocompetent cells within the cultured intestinal mucosa, namely the mucosal lymphocyte populations. In inflamed mucosa from patients with Crohn's disease, increased expression of relevant markers of T lymphocyte activation such as CD25 and TNF- $\alpha$ has been demonstrated in previous investigations. ${ }^{40-43}$ Interestingly, coculture of inflamed tissue with $L$ casei or $L$ bulgaricus significantly reduced the number of CD4+ cells among IEL. Moreover, the number of IEL producing TNF- $\alpha$ was also reduced by coculture of the tissue with $L$ casei or $L$ bulgaricus. Finally, LPL of inflamed tissues incubated with either bacterial strain showed a reduced display of the CD25 marker. These results suggest that cross talk between bacteria and mucosal cells does exist, and that certain bacteria downregulate the degree of activation of intestinal lymphocytes. It should be emphasised that the anti-inflammatory effect was only recognised in a setting of high immunoinflammatory activity, as is the case with tissue from active Crohn's disease, but not in non-inflamed control tissue.
In summary, in the present study we have established that certain probiotic bacteria are capable of interacting with immunocompetent cells using the mucosal interface and thus can modulate locally the production of proinflammatory cytokines by inflamed tissue. Our findings provide a basis for future clinical trials of probiotic bacteria in the treatment of active Crohn's disease.

\section{ACKNOWLEDGEMENTS}

Dr Marta P Llopis contributed to this work with considerable participation in the microbiological studies. Lactobacillus casei DN1 14001 and Lactobacillus bulgaricus LB10 were kindly provided by Dr Puri Relano (Danone Vtapole, Paris, France). Lactobacillus crispatus was kindly provided by Dr Antonia Andreu (Microbiology, Hospital Vall d'Hebron), and the $E$ coli strain was provided by Professor Juan Aguilar (Biochemistry, Faculty of Pharmacy, University of Barcelona). The authors are grateful to Montserrat Casellas and Milagros Gallart for their expert technical assistance. The project was supported by a grant from Danone Vitapole (Paris, France) and by Generalitat de Catalunya (RE: 2000SGR 00123).

\section{Authors' affiliations}

N Borruel, M Carol, F Casellas, M Antolín, F Guarner, J R

Malagelada, Digestive System Research Unit, Hospitals Vall d'Hebron, Autonomous University, Barcelona, Spain

F de Lara, E Espín, J Naval, Department of Surgery, Hospitals Vall d'Hebron, Autonomous University, Barcelona, Spain

\section{REFERENCES}

1 Podolsky DK. Inflammatory Bowel Disease. N Engl J Med 1991;325:928-37.

2 Van Deventer SJ. Tumour necrosis factor and Crohn's disease. Gut 1997:40:443-8.

3 Targan SR. Biology of inflammation in Crohn's disease: Mechanisms of action of anti-TNF- $\alpha$ therapy. Can J Gastroenterol 2000;14(suppl C): 13-6C.

4 Reinecker HC, Steffen $M$, Witthoeft T, et al. Enhanced secretion of tumour necrosis factor- $\alpha$, IL-6, and IL-1 $\beta$ by isolated lamina propria mononuclear cells from patients with ulcerative colitis and Crohn's disease. Clin Exp Immunol 1993;94:174-81.

5 Breese EJ, Michie CA, Nicholis SW, et al. Tumor necrosis factor alpha-producing cells in the intestinal mucosa of children with inflammatory bowel disease. Gastroenterology 1994;106:1455-66.

6 Reimund JM, Wittersheim C, Dumont S, et al. Increased production of tumour necrosis factor- $\alpha$, interleukin- $1 \beta$, and interleukin- 6 by morphologically normal intestinal biopsies from patients with Crohn's disease. Gut 1996;39:684-9.

7 Dionne S, Hiscott J, D'Agata I, et al. Quantitative PCR analysis of TNF- $\alpha$ and IL-1 $\beta$ mRNA levels in pediatric IBD mucosal biopsies. Dig Dis Sci 1997;42:1557-66

8 Woywodt A, Ludwig D, Neustock P, et al. Mucosal cytokine expression, cellular markers and adhesion molecules in inflammatory bowel disease. Eur J Gastroenterol Hepatol 1999:11:267-76.

9 Stack WA, Mann SD, Roy AJ, et al. Randomised controlled trial of CDP571 antibody to tumour necrosis factor- $\alpha$ in Crohn's disease. Lancet 1997;349:521-4.

10 Targan SR, Hanauer SB, van Deventer SJ, et al. A short-term study of chimeric monoclonal antibody cA2 to tumor necrosis factor- $\alpha$ for Crohn's disease. Crohn's Disease cA2 Study Group. N Engl J Med 1997;337:1029-35

11 Baert FJ, D'Haens GR, Peeters M, et al. Tumor necrosis factor alpha antibody (infliximab) therapy profoundly down-regulates the inflammation in Crohn's ileocolitis. Gastroenterology 1999;1 16:22-8.

12 D'Haens G, Van Deventer S, Van Hogezand R, et al. Endoscopic and histological healing with infliximab anti-tumor necrosis factor antibodies in Crohn's disease: A European Multicenter Trial. Gastroenterology 1999; 116:1029-34.

13 Rutgeerts $\mathbf{P}, D^{\prime}$ Haens $G$, Targan S, et al. Efficacy and safety of retreatment with anti-tumor necrosis factor antibody (infliximab) to maintain remission in Crohn's disease. Gastroenterology 1999; 117:761-9.

14 Ricart E, Panaccione R, Loftus EV, et al. Successful management of Crohn's disease of the ileoanal pouch with infliximab. Gastroenterology 1999:1 17:429-32.

15 Nikolaus S, Raedler A, Kuhbacker T, et al. Mechanisms in failure of infliximab for Crohn's disease. Lancet 2000;356:1475-9.

16 Plevy SE, Landers CJ, Prehn J, et al. A role for TNF-alpha and mucosal T helper-1 cytokines in the pathogenesis of Crohn's disease. J Immunol 1997; 159:6276-82.

17 Ina K, Itoh J, Fukushima K, et al. Resistance of Crohn's disease T cells to multiple apoptotic signals is associated with a Bcl-2/Bax mucosal imbalance. J Immunol 1999;163:1081-90.

18 Fiocchi C. Inflammatory bowel disease: etiology and pathogenesis. Gastroenterology 1998;115:182-206. 
19 Pirzer U, Schönhaar A, Fleischer B, et al. Reactivity of infiltrating T lymphocytes with microbial antigens in Crohn's disease. Lancet 1991;338:1238-9

20 Macpherson A, Khoo UY, Forgacs I, et al. Mucosal antibodies in inflammatory bowel disease are directed against intestinal bacteria. Gut 1996:38:365-75

21 Videla S, Vilaseca J, Guarner F, et al. Role of intestinal microflora in chronic inflammation and ulceration of the rat colon. Gut 1994:35:1090-7.

22 García-Lafuente A, Antolín M, Guarner F, et al. Incrimination of anaerobic bacteria in the induction of experimental colitis. Am J Physiol 1997;272:G10-15.

23 Mourelle $M$, Salas A, Guarner F, et al. Stimulation of transforming growth factor- $\beta 1$ by enteric bacteria in the pathogenesis of rat intestinal fibrosis. Gastroenterology 1998;114:519-26.

24 Kühn R, Löhler J, Rennick D, et al. Interleukin-10-deficient mice develop chronic enterocolitis. Cell 1993;75:263-74.

25 Madsen KL, Doyle JS, Jewell LD, et al. Lactobacillus species prevents colitis in interleukin 10 gene-deficient mice. Gastroenterology 1999:116:1107-14.

26 Umesaki Y, Setoyama H, Matsumoto S, et al. Expansion of alpha beta T-cell receptor-bearing intestinal intraepithelial lymphocytes after microbial colonization in germ-free mice and its independence from thymus. Immunology 1993;79:32-7.

27 Helgeland L, Vaage JT, Rolstad B, et al. Microbial colonization influences composition and T-cell receptor $\mathrm{V}$ beta repertoire of intraepithelial lymphocytes in rat intestine. Immunology 1996;89:494-501

28 Haller D, Bode C, Hammes WP, et al. Non-pathogenic bacteria elicit a differential cytokine response by intestinal epithelial cell/leucocyte co-cultures. Gut 2000;47:79-87

29 Guerin-Danan C, Chabanet C, Pedone C, et al. Milk fermented with yogurt cultures and Lactobacillus casei compared with yogurt and gelled milk: influence on intestinal microflora in healthy infants. Am J Clin Nutr 1998;67:111-17.

30 Pedone CA, Bernabeu AO, Postaire ER, et al. The effect of supplementation with milk fermented by Lactobacillus casei (strain DN-1 14001 ) on acute diarrhoea in children attending day care centres. Int J Clin Pract 1999;53:179-84.
31 Osset J, Bartolome RM, Garcia E, et al. Assessment of the capacity of Lactobacillus to inhibit the growth of uropathogens and block their adhesion to vaginal epithelial cells. J Infect Dis 2001;183:485-91.

32 Ochman H, Selander RK. Standard reference strains of Escherichia coli from natural populations. J Bacteriol 1984;154:690-3.

33 Carol M, Lambrechts A, Van Gossum A, et al. Spontaneous secretion of interferon $\gamma$ and interleukin 4 by human intraepithelial and lamina propria gut lymphocytes. Gut 1998;42:643-9.

34 Krieg AF, Gorton S, Henry JB. Effect of temperature on activity and lactate optima of LDH isoenzymes. Clin Chim Acta 1967;17:363-6.

35 Finnie IA, Dwarakanath AD, Taylor BA, et al. Colonic mucin synthesis is increased by sodium butyrate. Gut 1995;36:93-9.

36 Baricault L, Denariaz G, Houri JJ, et al. Use of HT-29, a cultured human colon cancer cell line, to study the effect of fermented milks on colon cancer cell growth and differentiation. Carcinogenesis 1995; 16:245-52.

37 Marin ML, Tejada-Simon MV, Lee JH, et al. Stimulation of cytokine production in clonal macrophage and T-cell models by Streptococcus thermophilus: comparison with Bifidobacterium sp. and Lactobacillus bulgaricus. J Food Prot 1998;61:859-64

38 Miettinen $M$, Lehtonen A, Julkunen I, et al. Lactobacilli and streptococci activate $N F-\kappa \beta$ and STAT signaling pathways in human macrophages. J Immunol 2000; 164:3733-40.

39 Tejada-Simon MV, Ustunol Z, Pestka JJ. Ex vivo effects of lactobacilli, streptococci, and bifidobacteria ingestion on cytokine and nitric oxide production in a murine model. J Food Prot 1999;62:162-9.

40 Pallone F, Fais S, Squarcia O, et al. Activation of peripheral blood and intestinal lamina propria lymphocytes in Crohn's disease. In vivo state of activation and in vitro response to stimulation as defined by the expression of early activation antigens. Gut 1987:28:745-53.

41 Choy MY, Walker-Smith JA, Williams CB, et al. Differential expression of CD25 (interleukin-2 receptor) on lamina propria T cells and macrophages in the intestinal lesions in Crohn's disease and ulcerative colitis. Gut 1990;31:1365-70.

42 Schreiber S, MacDermott RP, Raedler A, et al. Increased activation of isolated intestinal lamina propria mono-nuclear cells in inflammatory bowel disease. Gastroenterology 1991;101:1020-30.

43 Mariani P, Bachetoni A, D'Alessandro M, et al. Effector Th-1 cells with cytotoxic function in the intestinal lamina propria of patients with Crohn's disese. Dig Dis Sci 2000;45:2029-35. 